SERUM and BALF (bronchoalveolar lavage fluid) IL-8 levels and serum levels were investigated in Toxocara canis infected guinea-pigs and the role of IL-5 as a modulator of cytokine secretion was studied. Serum levels increased early in infected animals, exceeding control levels $4 \mathrm{~h}$ after infection, peaked between days 6 and 18 , and continued to exceed control levels after 48 days of in fection. Serum and BALF IL-8 levels showed the same profile as blood eosinophilia, increasing 6 days post-infection and peaking between days 18 and 24. Treatment of infected animals with anti-IL-5 Ab suppressed eosinophilia with a parallel increase in blood IL-8 levels, whereas no change was found in levels. To support our in vivo observation we carried out ex perim en ts in vitro using guin ea-pig LPSstimulated adherent peritoneal cells which release large amounts of IL-8 in to the supernatants. When rIL-5 was added to LPS-stimulated cells, 65\% inhibition of IL-8 release into the supernatants was observed. Pre-incubation of cells with anti-IL-5 Ab prevented the inhibition of IL-8 release in to the supernatants induced by rIL-5. Our results demonstrate for the first time that TNF- $\alpha$ and IL-8 are released concomitant with or after IL- 5 in the eosinophilic inflammation induced by $T$. canis. Moreover, in addition to showing that IL-5 is fundamental for the induction of blood eosinophilia, the present results suggest that this cytokine may play a new biological role by acting as modulator of IL-8 secretion.

Key words: Interleukins, Eosinophils, Inflammation, Toxocara canis

\section{Interleukin-5 modulates interleukin-8 secretion in eosinophilic inflammation}

\author{
L. H. Faccioli, ${ }^{1, C A}$ A. I. Medeiros, ${ }^{1}$ A. Malheiro, ${ }^{1}$ \\ R. C. L. R. Pietro, ${ }^{1}$ A. Januário ${ }^{1}$ and B. B. Vargaftig ${ }^{2}$
}

${ }^{1}$ Department of Parasitology, Microbiology and Immunology, School of Medicine of Ribeirão Preto, University of São Paulo, Ribeirão Preto, SP, Brazil;

${ }^{2}$ Unité de Pharmacologie Cellulaire, Unité Associée Institut Pasteur/INSERM n. 285, Paris, France

\footnotetext{
${ }^{\mathrm{CA}}$ Corresponding Author

Fax: (+55) 166336631

Email: facciol@fmrp.usp.br
}

\section{Introduction}

Eosinophilia has been associated with parasitic diseases, particularly when the parasites invade the tissue or injure the mucosal surfaces. ${ }^{1}$ Toxocara canis is an intestinal parasite of dogs and is the most common aetiologic agent of visceral larva migrans syndrome in humans. Beaver et al, ${ }^{2}$ when describing this syndrome, noted intense eosinophilia which reached more than $90 \%$ of total leukocyte counts. Despite previous observations that IL-5 participates in T. canis-induced eosinophilia ${ }^{3}$ and drives eosinophils from the bone marrow to blood, ${ }^{3}$ little is known about the presence of other cytokines related to eosinophil recruitment and the physiological control of blood eosinophilia in this parasitic model.

Using the well established guinea-pig model of $T$. canis infection, ${ }^{3}$ we determined the release of two relevant cytokines, TNF- $\alpha$ and IL-8, and studied their interaction with IL-5. This cytokine is an inducible glycoprotein produced and secreted by T cells, mast cells and eosinophils, ${ }^{4}$ which promotes the differentiation and proliferation of eosinophils ${ }^{5}$ and plays an essential role in the induction of eosinophilia in allergic inflammation, ${ }^{6}$ asthma, ${ }^{7}$ viruses, ${ }^{8}$ and helminthic infection. ${ }^{3,9,10}$ Anti-IL-5 Ab treatment inhibited blood and tissue eosinophilia., ${ }^{3,10,11}$ IL-8 is a member of the C-X-C chemokines described as neutrophil chemotactic factor ${ }^{12}$ which also attracts eosinophils. ${ }^{13,14}$ IL-8 is synthesized by monocytes, ${ }^{12}$ eosinophils, ${ }^{15}$ and other cells in response to several stimulus. IL-8 is an important mediator of lung disease $\mathrm{e}^{16}$ and may be relevant in asthma. ${ }^{17}$ Finally, TNF- $\alpha$ is an important mediator of inflammation produced in response to various stimuli such as bacteria, ${ }^{18}$ fungi, ${ }^{19}$ and allergen challenge. ${ }^{20} \mathrm{TNF}-\alpha$ is also involved in eosinophil recruitment ${ }^{21,22}$ and induces in vivo and in vitro IL-8 release. ${ }^{23,24}$

In the present study we first investigated whether TNF- $\alpha$ and IL- 8 are released during T. canis-induced eosinophilic inflammation in guinea-pigs. Since during the course of infection we observed a sequential release of TNF- $\alpha$ and IL- 8 in connection with IL-5 release, ${ }^{3}$ we also examined the relationship between IL-5 levels and IL-8 and TNF- $\alpha$ release in vivo by inducing IL-5 depletion with anti-IL-5 Ab. To corroborate the results obtained in vivo we carried out experiments in vitro studying the effect of rIL-5 on IL- 
8 release in supernatants of LPS-stimulated adherent peritoneal cells.

\section{Material and Methods}

\section{Reagents, MAbs and cytokines}

Human rIL-5 was a kind gift from Dr S. Poole, National Institute for Biological Standards and Control (NIBSB), UK. The rat MAb TRFK-5 was initially provided by Dr P. Minoprio, Institut Pasteur, Paris, and later raised and purified by Mrs M. A. Nahori (Institut Pasteur, Paris). Irrelevant antibody was rat $\operatorname{IgG}$ against total antihuman IgG. LPS from E. coli 0111:B4 was from Sigma (Sigma Chemical Co., St Louis, MO, USA) and thioglycollate medium was from Difco (USA). Cytokines were measured using commercially available ELISA kits (Quantikine-R \& D System, Minneapolis, MN). The kits were sensitive to human IL-8 and TNF- $\alpha$ levels of $5 \mathrm{pg} / \mathrm{ml}$ and $4.8 \mathrm{pg} / \mathrm{ml}$, respectively.

\section{Animals}

Outbred albino female guinea-pigs weighing $300-400 \mathrm{~g}$ were obtained from the University of São Paulo and kept in the animal house of the Department of Parasitology, Microbiology and Immunology, School of Medicine of Ribeirão Preto, under routine conditions.

\section{Infection of animals}

T. canis eggs were obtained from gravid female worms recovered from dogs. The eggs were removed from the uterus, washed and allowed to develop to the infective stage in shallow dishes containing $0.5 \%$ formalin at $37^{\circ} \mathrm{C}^{3}$ Guinea-pigs were infected with $1 \mathrm{ml}$ saline containing $500 \mathrm{~T}$. canis eggs, by gastric intubation using a metal cannula, under light ether anaesthesia. Guinea-pigs receiving $1 \mathrm{ml}$ of saline orally were used as control.

\section{Blood cell determination and serum collection}

Blood was obtained and cell counts were performed as previously described. ${ }^{3}$ Briefly, guinea-pigs were anaesthetized with sodium pentobarbitone $(30 \mathrm{mg} /$ $\mathrm{kg}$, i.v.) and blood samples were collected by cardiac puncture. A sample was immediately added to a tube containing Turk solution and total cell counts were carried out using a Neubauer chamber. Another sample was used to prepare a smear, and differential counts were obtained using Rosenfeld-stained slices. Five $\mathrm{ml}$ of blood was allowed to coagulate and the serum separated and kept at $-20^{\circ} \mathrm{C}$.
Bronchoalveolar lavage fluid (BALF) and femur flushing liquid

Infected and non-infected guinea-pigs killed with overdose of sodium pentobarbitone and $5 \mathrm{ml}$ of phosphate-buffered saline (PBS) containing 0.5\% sodium citrate (PBS/SC) were instilled through a polyethylene cannula introduced into the trachea. ${ }^{3}$ The cell-free supernatants were recovered immediately and kept at $-20^{\circ} \mathrm{C}$. Femur flushing liquid was collected from guinea-pigs using $5 \mathrm{ml}$ of $\mathrm{PBS} / \mathrm{SC}$, and cell free fluid was stored at $-20^{\circ} \mathrm{C}$.

\section{$B A L$, femur flushing liquid and serum cytokine determinations}

Serum, BALF and femur flushing fluid were used to measure IL-8-like and TNF- $\alpha$ like concentration using human ELISA kits.

\section{TRFK-5 treatments in vivo}

T. canis-infected guinea-pigs were injected i.p. with TRFK-5, an anti-IL-5 Ab, only once $(2 \mathrm{mg} / \mathrm{animal})$ at the time of infection (protocol A, PrA). Another group of infected animals received several i.p. anti-IL-5 $\mathrm{Ab}$ treatments at different intervals $(1 \mathrm{mg} / \mathrm{animal})$ at the time of infection followed by $0.3 \mathrm{mg} / \mathrm{animal}$ on days $1,3,12$ and 17 the reafter (protocol B, PrB). A group of T. canis infected guinea-pigs was treated with irrelevant $\mathrm{Ab}$ using PrB. A group of infected guinea-pigs without treatment and a group of non infected animals were used for comparison. All animals were sacrificed 18 days after administration of T. canis eggs.

\section{Preparation of adherent peritoneal cells and IL-8 generation in vitro}

Peritoneal exudate cells were obtained from outbred female guinea-pigs $(300 \mathrm{~g}) 4$ days after an i.p. injection of $10 \mathrm{ml}$ of $3 \%$ thioglycollate (Difco). Guinea-pigs were sacrificed with an overdose of sodium pentobarbitone and the cells were harvested from the peritoneal cavities by injection of $20 \mathrm{ml}$ of RPMI 1640 (Gibco BRL, Grand Island) containing $10 \mathrm{U} / \mathrm{ml}$ of heparin without FCS. The peritoneal exudate consisted of $95-98 \%$ mononuclear cells (macrophages and lymphocytes) on the basis of morphology determined by light microscopy examination of Rosenfeldstained cytospin preparations. The cells were harvested from four individual guinea-pigs and added to separate plates $\left(2 \times 10^{6}\right.$ cells/well, in a $24-w e l l$ polypropylene plate from Costar, Cambridge, MA; cell viability $90-95 \%$ as determined by Trypan blue) and incubated for $2 \mathrm{~h}$ at $37^{\circ} \mathrm{C}$, at $5 \% \mathrm{CO}_{2}$, in RPMI 1640 culture medium supplemented with $50 \mathrm{U} / \mathrm{ml}$ penicillin, $50 \mu \mathrm{g} / \mathrm{ml}$ streptomycin and $2 \mathrm{mmol} / \mathrm{ml} 2$-mer- 

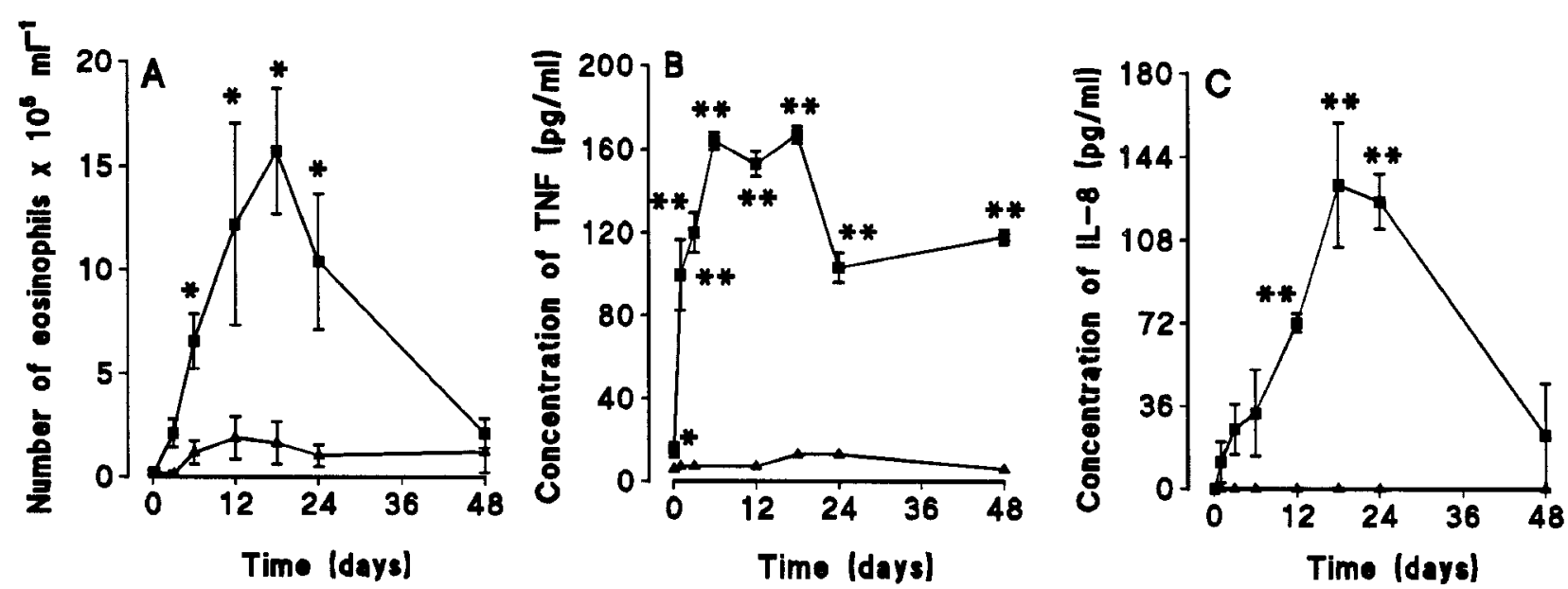

FIG. 1. Blood eosinophil counts (A) and serum TNF- $\alpha$ (B), and IL-8 (C) levels in $T$. canis-infected guinea-pigs sacrificed at different times post-infection ( $\boldsymbol{n}=4-5$ per day). Asterisks indicate a significant difference between infected ( $\square$ ) and noninfected animals $(\mathbf{\Delta}) .{ }^{*} P<0.05$ and ${ }^{* *} P<0.01$.

captoethanol. The adherent cells were washed three times with medium to remove non-adherent cells. The monolayers of adherent cells were pre-incubated with RPMI 1640 medium supplemented with antibiotics and $10 \%$ FCS with or without anti-IL-5 Ab $(0.17 \mathrm{ng} / \mathrm{ml}$ or $17 \mathrm{ng} / \mathrm{ml}$ ) over a period of $15 \mathrm{~min}$. Thereafter, medium or rIL-5 $(0.5 \mathrm{ng} / \mathrm{ml}$ or $10 \mathrm{ng} / \mathrm{ml})$ was added to the culture, and after $15 \mathrm{~min}$ of incubation the cells were stimulated or not with LPS $(500 \mathrm{ng} / \mathrm{ml})$. The plates were incubated for an additional $6-8 \mathrm{~h}$ at $37^{\circ} \mathrm{C}$, $5 \% \mathrm{CO}_{2}$. The cell-free supernatants were collected, separated and kept at $-20^{\circ} \mathrm{C}$ until the measurement of IL-8. The results were expressed as cytokine concentration $(\mathrm{pg} / \mathrm{ml})$ in supernatants of LPS-stimulated cells submitted to different treatments minus the concentration of cytokine released by cells incubated with medium alone. All the experiments were performed under aseptic conditions.

\section{Statistical analysis}

Data are presented as the mean \pm SEM and were analysed statistically by the Student's two-tailed $t$-test for differences between infected and non-infected animals, or between infected untreated and treated guinea-pigs. A $P<0.05$ value was considered to be statistically significant. In vitro results were analysed statistically by the Student's two-tailed $t$-test and by ANOVA test.

\section{Results}

Blood eosinophil counts and serum TNF- $\alpha$ and IL-8 levels during $T$. canis infection

As shown in Fig. 1, T. canis-infected guinea-pigs developed blood eosinophilia (Fig. 1A) and had increased circulating TNF- $\alpha$ (Fig. 1B) and IL-8 (Fig. 1C) levels. Blood eosinophilia increased significantly on day 12 and peaked by day 18 post-infection. Serum TNF- $\alpha$ levels increased $4 \mathrm{~h}$ after egg inoculation and became significantly higher $24 \mathrm{~h}$ later were still increased by day 3, peaked between days 6 and 18 and remained above control levels up to 48 days postinfection. TNF- $\alpha$ in the serum of non-infected animals was $8 \pm 1 \mathrm{pg} / \mathrm{ml}, n=9$. Serum IL-8 concentration showed the same profile as blood eosinophilia, but increased significantly only on day 12 post-infection, reaching a peak between days 18 and 24 and decreasing by day 48 . In this set of experiments, no IL8 was detectable in the serum of non-infected guineapigs $(n=7)$.

\section{BALF and femur flushing liquid IL-8 levels}

BALF and bone marrow IL-8 levels were also determined during T. canis infection, and the results are shown in Fig. 2. BALF IL-8 levels were not detectable on day 3 but increased significantly on day 6 postinfection $(41.3 \pm 14.5 \mathrm{pg} / \mathrm{ml})$, and reached a plateau between days 12 and $24(72.2 \pm 8.4 \mathrm{pg} / \mathrm{ml}$ on day 12 , $72.5 \pm 21.8 \mathrm{pg} / \mathrm{ml}$ on day 18 ; and $64.1 \pm 10.9 \mathrm{pg} / \mathrm{ml}$ on day 24) post-infection. BALF IL-8 in non-infected guinea-pigs and femur flushing liquid IL-8 in T. canis infected guinea-pigs were not detectable at any of the times studied.

\section{Effects of in vivo anti-IL-5 Ab treatment on IL-8 secretion}

Having demonstrated that eosinophilia in T. canisinfected guinea-pigs is correlated with IL- $5,{ }^{3}$ and IL-8 secretion, we investigated the effect of IL-5 inhibition on TNF- $\alpha$ and IL-8 release into the serum of infected guinea-pigs. The i.p. injections of anti-IL-5 Ab (TRFK-5) into T. canis-infected guinea-pigs using the $\operatorname{PrA}$ (single 


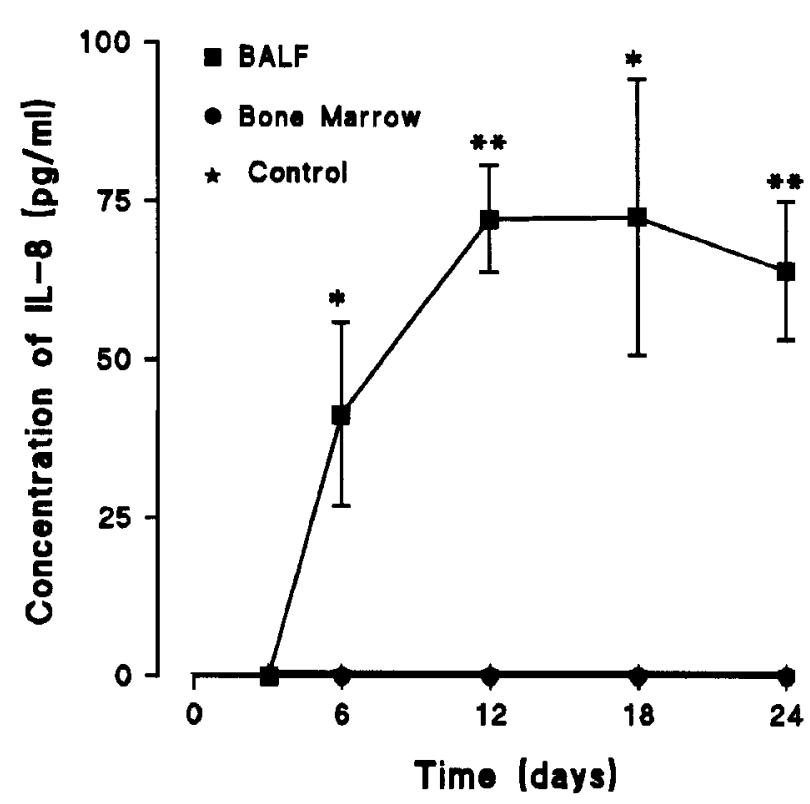

FIG. 2. BALF and bone marrow IL-8 levels in $T$. canis infected guinea-pigs sacrificed on different days post-infection $(n=3$ per day). Asterisks indicate a significant difference between infected $(\square)$ and non-infected $(\star)$ animals. ${ }^{*} P<0.05$ and ${ }^{* *} P$ $<0.01$.

dose) and PrB (several doses) protocols inhibited blood eosinophil counts by $97 \%$ to $99 \%$ as shown in Table 1 . When the animals were treated with a single dose of anti-IL-5 Ab, PrA, a 159\% increase in IL-8 was observed in serum (Table 1, range 101-234\% of control; $n=6$ animals, obtained in two different sets of experiments). Moreover, when infected animals were treated with $\operatorname{PrB}$, eosinophilia was also suppressed and serum IL-8 levels were increased by $216 \%$ (Table 1, range 128-329\% of control, $n=6$, obtained in two sets of experiments). By contrast, no alteration in serum TNF- $\alpha$ concentration was observed whatever the treatment (Table 1, T. canis-infection without treatment $n=7$, obtained from two set of experiments; anti-IL-5 Ab given once $n=3$; several anti-IL-5 Ab injections $n=5)$. Infected animals treated with irrelevant $\mathrm{Ab}$ presented nonsignificant differences in serum IL-8 $(n=3)$ and TNF- $\alpha$ levels $(n=3)$. Serum IL-8 and TNF- $\alpha$ levels of non-infected animals were $14 \pm 10$

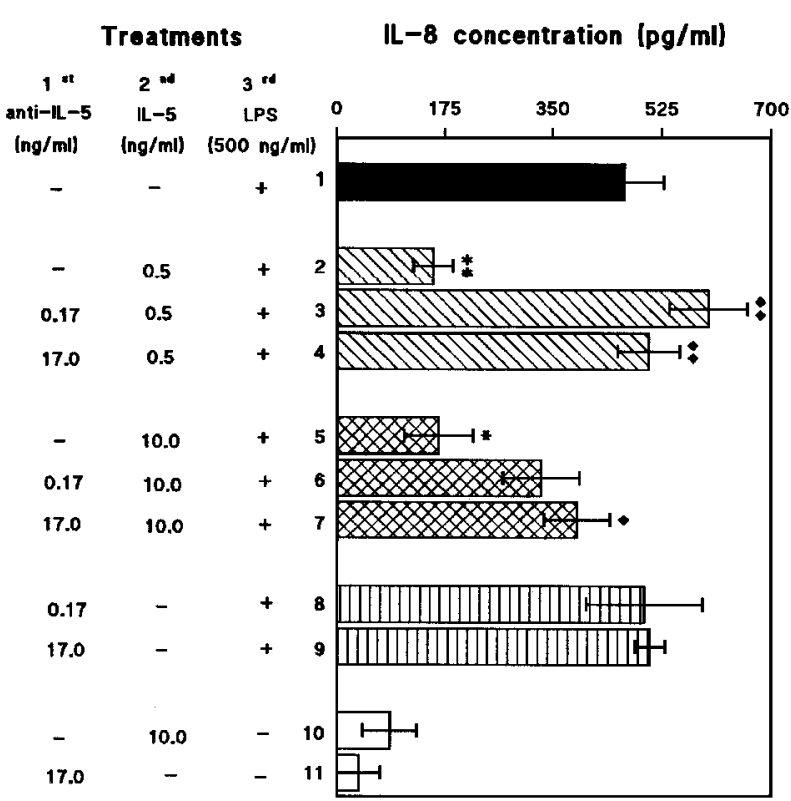

FIG. 3. Inhibition of IL-8 release into supernatants of LPSstimulated guinea-pig adherent peritoneal cells pre-treatment with rlL-5. Data are as means $\pm \operatorname{SEM}(n=4)$. Asterisks indicate differences between the amount of IL-8 released by LPS-stimulated adherent peritoneal cells pre-incubated with or without $\mathrm{rlL}-5,{ }^{*} P<0.05$ and ${ }^{* *} P<0.01$. Diamond s indicate differences in the amount of IL-8 released by LPS-stimulated adherent peritoneal cells pretreated with $\mathrm{rlL}-5$ in the absence or presence of anti-IL-5 Ab, $P<0.05$ and $\leftrightarrow P<$ 0.01 .

and $8 \pm 1 \mathrm{pg} / \mathrm{ml}$, receptively; $n=6$, obtained from two sets of experiments.

\section{IL-5 downregulates IL-8 secretion in vitro}

In order to clarify the in vivo experiments, in vitro experiments were performed using adherent peritoneal cells stimulated with LPS, a potent inductor of IL8 secretion. ${ }^{12}$ IL- 8 was determined in supernatants of LPS-stimulated guinea-pig adherent peritoneal cells pre-incubated with or without rIL-5. The amounts of IL-8 released by adherent peritoneal cells stimulated with LPS $(500 \mathrm{ng} / \mathrm{ml})$ were increased in the absence of rIL-5 (Fig. 3, column 1). In the presence of rIL-5 $(0.5 \mathrm{ng} / \mathrm{ml}$ or $10 \mathrm{ng} / \mathrm{ml}$; Fig. 3, columns 2 and 5) LPS-

Table 1. Blood eosinophil counts and serum TNF and IL-8 levels in T. canis infected guinea-pig untreated or treated with TRFK-5

\begin{tabular}{lccc}
\hline Treatment & Eosinophil counts & TNF (pg/ml) & IL-8 (pg/ml) \\
\hline Untreated $^{a}$ & $12.2 \pm 5.3 *$ & $116.7 \pm 12.0$ & $106.0 \pm 14.0^{* *}$ \\
Irrelevant Ab $^{a}$ & $13.3 \pm 4.5$ & $85.5 \pm 8.5$ & $121.0 \pm 9.0$ \\
TRFK-5 (PrA) & $0.2 \pm 0.2^{*}$ & $118.5 \pm 10.0$ & $274.4 \pm 42.0^{* *}$ \\
TRFK-5 (PrB) & $0.01 \pm 0.01^{*}$ & $134.0 \pm 12.0$ & $336.0 \pm 45.0^{* * *}$ \\
Non infected & $0.96 \pm 0.41$ & $8.0 \pm 1.0$ & $28.0 \pm 14.0$ \\
\hline
\end{tabular}

${ }^{a}$ The animals were sacrificed 18 days after administration of $500 \mathrm{~T}$. canis eggs by gastric intubation. In eosinophil counts the values represent mean \pm SEM $\times 10^{5} / \mathrm{ml}$. Diamonds indicate a significant difference between untreated infected animals and non-infected controls. ${ }^{\bullet} P<0.01$ and * $P<0.01$. Asterisks indicate a significant difference between untreated infected guinea-pigs and infected guinea pigs treated once (PrA) or five times (PrB) with anti-IL-5 Ab. ${ }^{*} P<0.05$ and ${ }^{* *} P<0.01$ and ${ }^{* * *} P<0.001$. 
induced IL-8 release was inhibited by $64 \%$ and $66 \%$ respectively. Pre-incubation of adherent cells with two concentration of anti-IL-5 Ab $(0.17 \mathrm{ng} / \mathrm{ml}$ or $17 \mathrm{ng} / \mathrm{ml}$; Fig. 3, columns 3, 4, 6 and 7) prevented the IL-8 inhibition induced by $10 \mathrm{ng} / \mathrm{ml}$ of rIL-5 (Fig. 3, columns 6 and 7) or $0.5 \mathrm{ng} / \mathrm{ml}$ (Fig. 3, columns 3 and 4). A non-significant increase in IL-8 release followed the addition of anti-IL $-5 \mathrm{Ab}(0.17 \mathrm{ng} / \mathrm{ml}$ or $17.0 \mathrm{ng} / \mathrm{ml}$; Fig. 3, columns 8 and 9) to LPS-stimulated cells. However, the addition of rIL-5 or anti-IL- $5 \mathrm{Ab}$ to cells without LPS failed to induce IL-8 release (Fig. 3, columns 10 and 11). Data are from $n=4$ animals.

\section{Discussion}

This study demonstrated that the inoculation of guinea-pigs with T. canis induces a sustained increase ofTNF- $\alpha$ levels in blood, and that the concentration of blood and BALF IL-8 increases later during infection, together with the number of circulating eosinophils. We demonstrated previously that $T$. canis-infected guinea-pigs present increased serum IL-5 levels followed by an increase in eosinophil numbers in blood and tissues which was suppressed by an anti-IL-5 $\mathrm{Ab}^{3}$

TNF- $\alpha$ levels increased very early in the serum of infected guinea-pigs, reaching levels $87 \%$ above those of noninfected animals $4 \mathrm{~h}$ after egg inoculation and remaining above controls up to 48 days post-infection. T. canis larvae persist in different organs for long periods of time in infected animals ${ }^{25}$ and release excretory-secretory antigens during migration as demonstrated before. ${ }^{26}$ The prolonged and sustained TNF- $\alpha$ activity in blood may thus be explained either by the persistent presence of larvae in the tissues and/ or by the release of those excretory-secretory antigens. Moreover, although TNF- $\alpha$ has been described as an inflammatory cytokine that appears first in the circulation in experimental sepsis and endotoxaemia and decreases a few hours after the stimulus, ${ }^{27,28}$ in chronic inflammation, as observed in mice injected with $\mathrm{BCG}^{29}$ Paracoccidioides brasiliensis, ${ }^{19}$ or Schistosoma mansoni eggs, ${ }^{30} \mathrm{TNF}-\alpha$ is present for a long time post-infection. Moreover, in patients with septic shock due to various Gramnegative bacteria, serum TNF- $\alpha$ remained elevated in nonsurvivors who were still alive at day 10 after hospitalization. ${ }^{31}$ Thus, the increase of TNF- $\alpha$ levels for a long period of time is not limited to the present experimental model.

TNF- $\alpha$ is involved in eosinophil recruitment ${ }^{21,22}$ and has also been reported to occur in diseases presenting elevated numbers of eosinophils, such as airway inflammation. ${ }^{22}$ Finally, bronchoalveolar leukocytes from patients with bronchial asthma secrete high levels of TNF- $\alpha{ }^{32}$ The observation that serum and BALF IL-8 levels started to increase only after serum $\mathrm{TNF}-\alpha$ release suggests that $\mathrm{TNF}-\alpha$ may be involved in the induction of IL-8 release in this model. Indeed, several reports have shown that TNF- $\alpha$ is a potent IL-8 inducer ${ }^{23,33}$ and IL-8 is present after TNF- $\alpha$ therapy in patients with chronic hepatitis. ${ }^{24}$

The serum and BALF levels of IL-8 in infected animals increased significantly only between 6 and 12 days post-infection and peaked between days 18 and 24. These increases occurred at the same time as the increase in circulating eosinophil numbers, and the decrease of IL-8 in serum was followed by a reduction in blood eosinophil counts. Although blood eosinophilia in T. canis-infected animals was suppressed by anti-IL-5 Ab treatment, even when the anti-IL-5 treatment was performed 1 day before the peak of eosinophilia, ${ }^{3}$ we may suppose that IL-8 contributed to eosinophil recruitment. IL-8 has been described as an eosinophil chemoattractant. ${ }^{13,14}$ However, it appears that IL-8 is only able to induce eosinophil migration after this cell being primed by IL-5. ${ }^{14,34}$ Also, our results showing that IL-8 release occurs only outside the bone marrow (Fig. 2), suggest that this cytokine probably works as an eosinophil chemoattractant and contributes for the recruitment of IL5-primed eosinophils from bone marrow to blood. Based on these data and on the data presented here, we suggest that IL-8 requires pre-priming with IL-5 to induce eosinophil recruitment in vivo. Thus, despite the release of high amounts of IL-8 in this model, the presence of IL-5 is essential for eosinophil migration, as demonstrated in antigen-challenged guinea-pigs ${ }^{6}$ and in vitro. ${ }^{14,34}$ However, the exact mechanisms involved in this process are not yet completely understood, and further studies using anti-IL-8 Ab will be essential to determine the contribution of IL-8 to the eosinophil recruitment and lung inflammation occurring in this model. ${ }^{3}$

Although TNF- $\alpha$ and IL-8 activities were measured in serum, BALF and supernatants of adherent peritoneal cells from guinea-pigs using a human ELISA kit, we think that the measurements refer to authentic guinea-pig cytokines presenting TNF- $\alpha$ and IL-8-like activities. TNF- $\alpha$ is highly conserved among species ${ }^{35}$ and supernatants of guinea-pigs adherent peritoneal cells stimulated with LPS killed $45 \pm 6 \%$ of WEHI cells in a cytotoxic assay, while supernatants from cells with only medium killed $4 \pm 4 \%$ of cells $(n=4$; data not shown); recombinant human IL-8 induces eosinophil migration when injected into the skin of guineapigs, ${ }^{13}$ IL-8 and TNF- $\alpha$ activities were also observed in the supernatants of guinea-pig adherent peritoneal cells after LPS stimulation, as observed in human cells. ${ }^{12,36,37}$ Moreover, eosinophil accumulation in guinea-pig skin induced by LPS was inhibited by antiTNF- $\alpha$ receptor, ${ }^{21}$ and serum IL- 8 and TNF- $\alpha$ levels were decreased in T. canis-infected guinea-pigs treated with dexamethasone (data not shown).

To better characterize the IL-5/IL-8 interactions we investigated the changes in serum TNF- $\alpha$ and IL-8 
levels in T. canis-infected guinea-pigs after IL-5 depletion by an anti-IL- $5 \mathrm{Ab}$. When IL-5 was thus suppressed in infected animals eosinophil counts were also reduced and serum IL-8 levels increased, in the absence of changes in serum TNF- $\alpha$ (Table 1). These results suggest that IL-5 downregulates the expression of IL-8. These in vivo data were confirmed by in vitro experiments: IL-8 production in the supernatants of LPS-treated adherent peritoneal cells in the presence or not of rIL-5 (Fig. 3). IL-8 release (Fig. 3) were increased by LPS, as reported. ${ }^{37}$ However, when rIL-5 was added to cells before LPS, a marked inhibition of IL-8 release occurred, which was prevented by anti-IL$5 \mathrm{Ab}$ treatment, demonstrating specificity. Also, these results were corroborated by the findings that rIL-5 added to LPS stimulated adherent peritoneal cell culture induced significant inhibition of mRNA IL-8 expression which was reversed by the addition of anti-IL-5 Ab (data not shown).

Thus, the inhibitory effects of IL- -5 on IL-8 secretion may represent an endogenous mechanism of downregulating eosinophil inflammation. It may be possible that IL-5 is required to prevent IL-8 over-production and release. Moreover, as discussed above, we suggest that serum IL-8 acts as an eosinophil chemoattractant in the presence of IL-5. However, since IL-5 is decreased during the course of infection an increase in serum IL-8 occurs which, above a certain level, may act as a modulator of eosinophil release from bone marrow and tissue eosinophil migration. Thus, it is possible that the increase of serum IL-8 levels in $T$. canis-infected guinea-pigs after anti-IL-5 Ab treatment contributes to the inhibition of eosinophilia. IL-8, which is chemotactic for neutrophils, inhibited the migration of these cells to the skin when administered at high concentrations by the iv. route. ${ }^{38}$ On the other hand, eosinophils have been described as tissueresident cells that remain only a few hours in the circulation, ${ }^{39}$ and this characteristic may explain why we did not find an increase in blood eosinophil counts after anti-IL-5 $\mathrm{Ab}$ treatment.

The present results, describing a new function of IL-5 as a modulator of IL-8 secretion, may be useful for a better understanding and control of diseases presenting eosinophilia and high $\mathrm{IgE}$ levels. ${ }^{1}$ IL-8 selectively inhibits $\operatorname{IgE}$ production ${ }^{40}$ and may be involved in the control of serum IgE levels in vivo. Production of high amounts of IL-5 in such diseases may downregulate IL-8 levels and consequently contribute to the maintenance of high $\operatorname{IgE}$ levels during infection. Thus, an anti-IL-5 $\mathrm{Ab}$ treatment might be useful both to inhibit eosinophil counts and to increase serum IL-8 production which down-regulates IgE secretion.

In summary, the results presented here demonstrate that in T.canis-induced eosinophilia there is a sequential release of TNF- $\alpha$ and IL- 8 occurring in parallel to or after serum IL-5 release. In this model,
IL-5 appears to be the main factor involved both in the induction of eosinophilia and in the in vivo control of IL-8 synthesis and production. Thus, IL-5 may also contribute to the increase of $\operatorname{IgE} E$ synthesis observed in parasitic diseases and allergy, in parallel to eosinophilia.

\section{References}

1. Nutman TB, Ottesen EA, Cohen SG. The eosinophil, eosinophilia, and eosinophil-related disorders. Allergy Proc 1989; 10: 47-62.

2. Beaver P, Snyder H, Carrera G, et al. Chronic eosinophilia due to visceral larva migrans. Paediatrics 1952; 9: 7-19.

3. Faccioli LH, Mokwa VF, Silva CL, et al. IL-5 drives eosinophils from bone marrow to blood and tissues in a guinea-pig model of visceral larva migrans syndrome. Mediators of Inflammation 1996; 5: 24-31.

4. Sanderson CL. Interleukin-5. In: Thomson AW, ed. The Cytokine Handbook. San Diego: Academic Press, 1994; 127-144.

5. Yamaguchi Y, Suda T, Suda J, et al. Purified interleukin 5 supports the terminal differentiation and proliferation of murine eosinophilic precursors. J Exp Med 1988; 167: 43-56.

6. Coëffier E, Joseph D, Vargaftig BB. Role of interleukin-5 in enhanced migration of eosinophils from airways of immunized guinea-pigs. $\mathrm{Br} J$ Pharmacol 1994; 113: 749-756.

7. Hamid Q, Azzawi M, Ying S, et al. Expression of mRNA for interleukin-5 in mucosal bronchial biopsies from asthma. J Clin Invest 1991; 87: 1541-1546.

8. Coyle AJ, Erard F, Bertrand C, et al. Virus-specific $\mathrm{CD}^{+}$cells can switch to interleukin 5 production and induce airway eosinophilia. J Exp Med 1995; 181 : 1229-1233.

9. Limaye AP, Abrams JS, Silver JE, et al. Regulation of parasite-induced eosinophilia: selectively increased interleukin 5 production in helminthinfected patients. J Exp Med 1990; 172: 399-402.

10. Coffman RL, Seymour BWP, Hudak S, et al. Antibody to interleukin-5 inhibits helminth-induced eosinophilia in mice. Science 1989; 245: 308-310.

11. Eum S-Y, Hailé S, Lefort J, et al. Eosinophil recruitment into the respiratory epithelium following antige nic challenge in hyper-IgE mice is accompanied by interleukin 5-dependent bronchial hyperresponsiveness. Proc Natl Acad Sci USA 1995; 92: 12290-12294.

12. Yoshimura, T, Matsushima K, Oppenheim JJ, et al. Neutrophil chemotactic factor produced by lipopolysaccharide (LPS)-stimulated human blood mononuclear leukocytes: partial characterization and separation from interleukin 1 (IL-1). J Immunol 1987; 139: 788-793.

13. Collins, PD, Weg VB, Faccioli LH, et al. Eosinophil accumulation induced by human interleukin-8 in the guinea-pig in vivo. Imm unology 1993; 79 : 312-318.

14. Sehmi R, Cromwell O, Wardlaw AJ, et al. Interleukin-8 is a chemoattractant for eosinophils purified from subjects with blood eosinophilia but not from normal healthy subjects. Clin Exp Allergy 1993; 23: 1027-1036.

15. Braun RK, Franchini M, Erard F, et al. Human peripheral blood eosinophils produce and release interleukin-8 on stimulation with calcium ionophore. Eur Immunol 1993; 23: 956-960.

16. Smith D, Burrows L, Westwick. J. Interleukin-8-a mediator of inflammatory lung disease? In: Westwick J, ed. Chemotactic Cytokines. New York: Plenum Press, 1991; 119-126.

17. Marini M, Vittori E, Hollemborg J, et al. Expression of the potent inflammatory cytokines, granulocyte-macrophage-colony-stimulating factor and interleukin-6 and interleukin-8, in bronchial epithelial cells of patients with asthma. J Allergy Clin Immunol 1992; 89: 1001-1009.

18. Havell EA. Evidence that tumor necrosis has an important role in antibacterial resistance. J Immunol 1989; 143: 2894-2899.

19. Figueiredo F, Alves LMC, Silva CL. Tumor necrosis factor production in vivo and in vitro in response to Paracoccidioides brasiliensis and the cell wall fractions thereof. Clin Exp Immunol 1993; 93: 189-194.

20. Ohkawara Y, Yamauchi K, Tanno Y, et al. Human lung mast cells and pulmonary macrophages produce tumor necrosis factor- $\alpha$ in sensitized lung tissue after IgE receptor triggering. Am J Respir Cell Mol Biol 1992; 7: 385-392.

21. Weg VB, Walsh DT, Faccioli LH. LPS-induced 111 -eosinophil accumulation in guinea-pig skin: evidence for a role for TNFa. Immunology 1995; 84: $36-40$.

22. Lukacs NW, Strieter RM, Chensue SW, et al. TNF $\alpha$ mediates recruitment of neutrophils and eosinophils during airway inflammation. J Immunol 1995; 154: 5411-5417.

23. Kunkel SL, Strieter RM, Chensue SW, et al. Tumor necrosis factor-alpha, interleukin-8 and chemotactic cytokines. Prog Clin Biol Res 1990; 349: 433-444.

24. Sheron N, Williams R. IL-8 as a circulating cytokine: induction by recombinant tumor necrosis factor-alpha. Cin Exp Immunol 1992; 89: $100-103$. 
25. Kayes SG, Oaks JA. Effect of inoculum size and length of infection on the distribution of Toxocara canis larvae in the mouse. Am J Trop Med and Hyg 1976; 25: 573-580.

26. Parsons JC, Bowman DD, Grieve RB. Tissue localization of excretorysecretory antigens of larval Tox ocara canis in acute and chronic murine toxocariasis. Am J Trop Med and Hyg 1986; 35: 974-981.

27. Cannon JG, Tompkins RG, Gelfand JA, et al. Girculating interleukin-1 and tumor necrosis factor in septic shock and experimental endotox in fever. J Infect Dis 1990; 161: 79-84.

28. van Deventer SJH, Buller HR, ten Cate JW, et al. Experimental endotoxemia in humans: analysis of cytokine release and coagulation, fibrinolytic, and complement pathways. Blood 1990; 76: 2520-2526.

29. Kindler V, Sappino AP, Grau GE, et al. The inducing role of tumor necrosis factor in the development of bactericidal granulomas during BCG infection. Cell 1989; 56: 731-740.

30. Chensue SW, Otterness IG, Higashi GI, et al. Monokine production by hypersensitivity (Schistosoma mansoni EGG) and foreign body (Sephadex bead)-type granuloma macrophages. Evidence for sequential production of IL-1 and tumor necrosis factor. J Immunol 1989; 142: 1281-1286.

31. Calandra T, Baumgartner J-D, Grau GE, et al. Prognostic values of tumor necrosis factor/cachectin, interleukin-1, interferon- $\alpha$, and Interferon- $\gamma$ in serum of patients with septic shock. J Infect Dis 1990; 161: 982-987.

32. Cembrzyanska-Novak M, Szklarz E, Inglot AD, et al. Elevated release of tumor necrosis factor-alpha and interferon-gamma by bronchoalveolar leukocytes from patients with bronchial asthma. Am Rev Respir Dis 1993; 147: 291-295.

33. Kwon OJ, AU BT, Collins PD, et al. Tumor necrosis factor-induced interleukin-8 expression in cultured human airway epithelial cells. Am J Physiol 1994; 267: L398-L405.
34. Moser R, Fehr J, Olgiati L, et al. Migration of primed human eosinophils across cytokine-activated endothelial cell monolayers. Blood 1992; 79: 2937-2945.

35. Ruddle NH. Tumor necrosis factor-beta/lymphotoxin-alpha. In: Thomson AW, ed. The Cytokine Handbook. San Diego: Academic Press, 1994; 305-315.

36. Becker S, Quay J, Soukup J. Cytokine (tumor necrosis factor, IL-6 and IL8) production by respiratory syncytial virus-infected human alveolar macrophages. J Imm unol 1989; 147: 4307-4312.

37. Girgis RE, Basha MA, Maliarik M, et al. Cytokines in bronchoalveolar lavage fluid of patients with active pulmonary sarcoidosis. Am J Respir Crit Care Med 1995; 152: 71-75.

38. Hechtman DH, Cybulsky MI, Fuchs HI, et al. Intravascular IL-8. Inhibitor of polymorphonuclear leukocyte accumulation at sites of acute inflammation. J Immunol 1991; 147: 883-892.

39. Weller PF, Goetzl EJ. The human eosinophil. Roles in host defence and tissue injury. Am J Pathol 1980; 100: 793-820.

40. Kimata H, Yoshida A, Ishioka C, et al. Interleukin 8 (IL-8) selectively inhibits immunoglobulin E production induced by IL 4 in human B cells. J Exp Med 1992; 176: 1227-1231.

ACKNOWLEDGEMENTS. This work was supported by a grant from Fundação de Amparo à Pesquisa do Estado de São Paulo-FAPESP, a grant from Conselho Nacional de Desenvolvimento Cientớfico e Tecnológico-CNPq, and Fundação de Apoio ao Ensino, Pesquisa e Assistência do Hospital das Clánicas da Faculdade de Medicina de Ribeirão Pre to-FAEPA, Brazil.

\section{Received 14 October 1997;} accepted in revised form 6 November 1997 


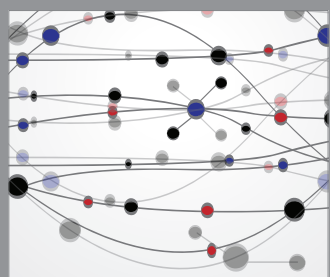

The Scientific World Journal
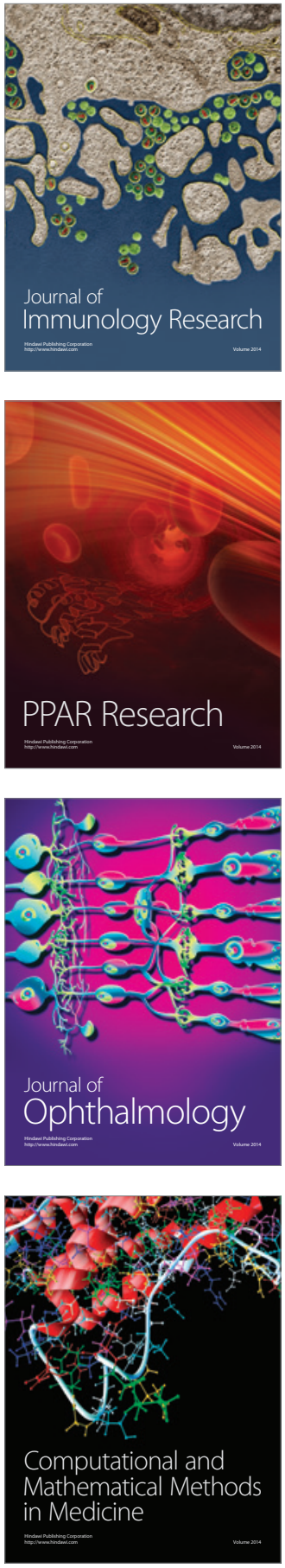

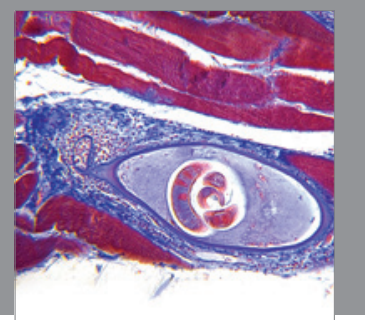

Gastroenterology

Research and Practice
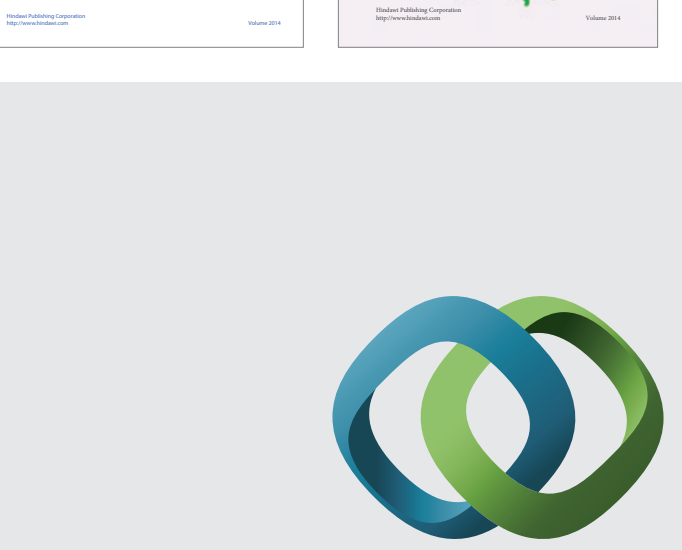

\section{Hindawi}

Submit your manuscripts at

http://www.hindawi.com
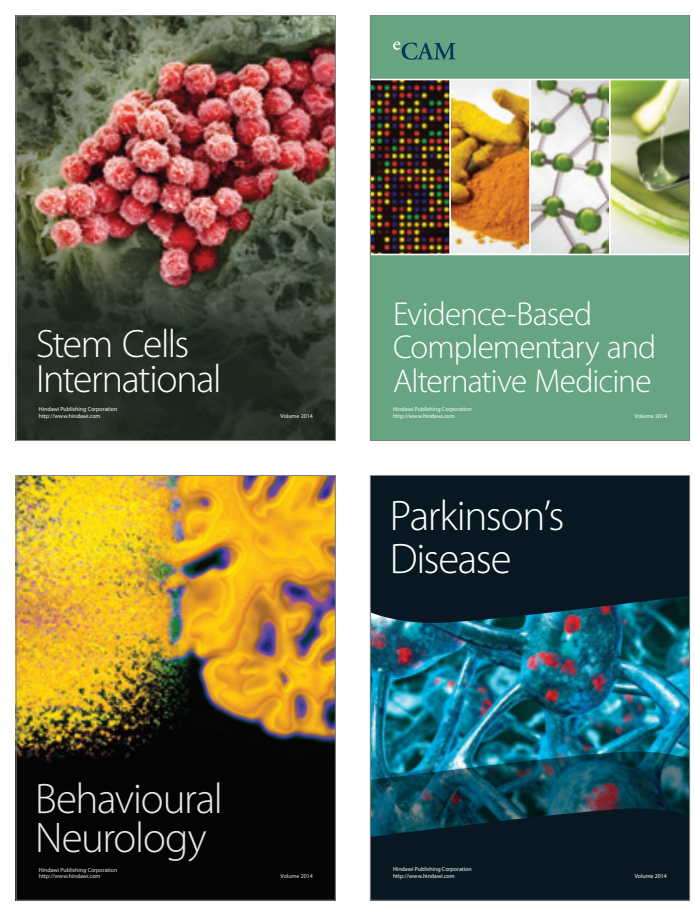

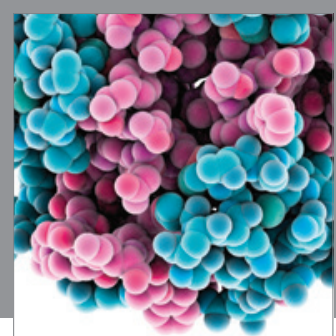

Journal of
Diabetes Research

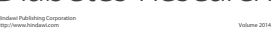

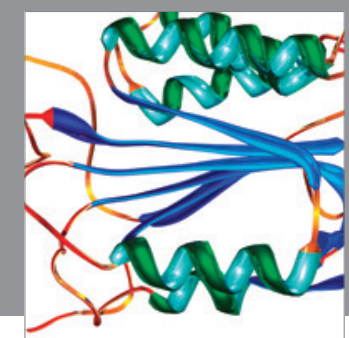

Disease Markers
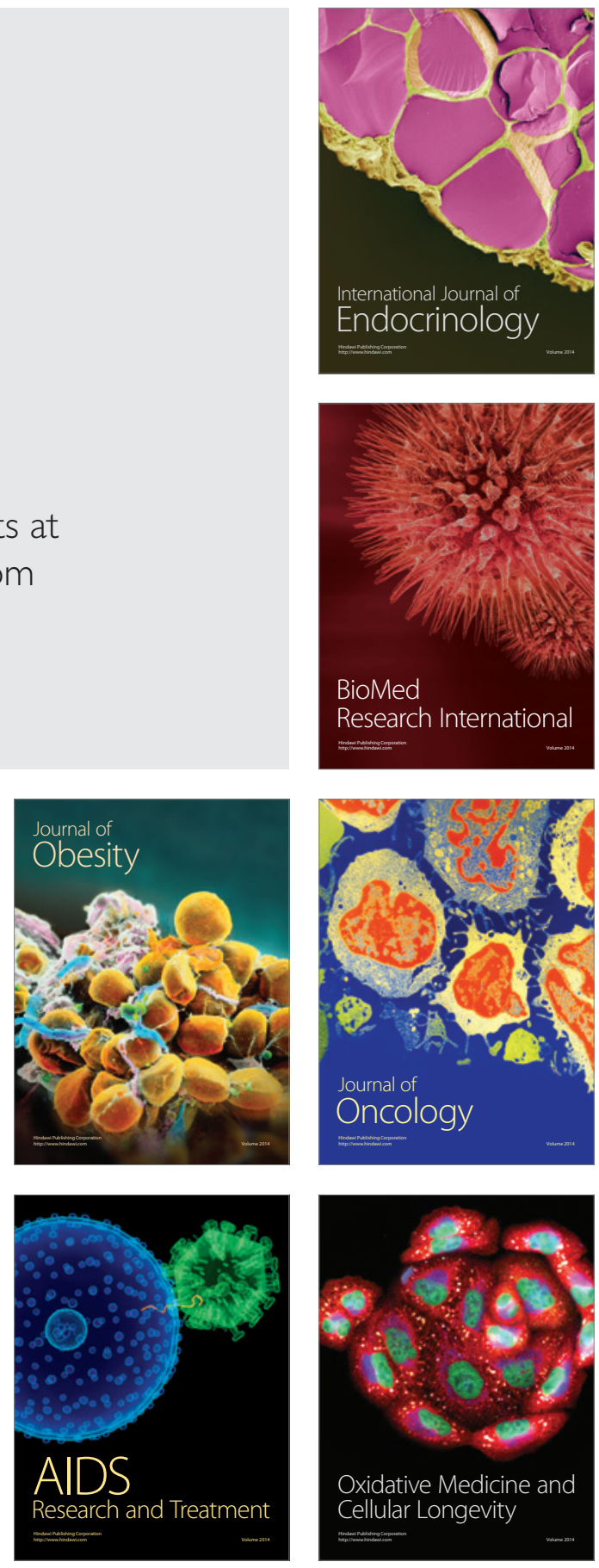